Check for updates

Cite this: RSC Adv., 2017, 7, 42946

Received 28th June 2017

Accepted 31st August 2017

DOI: 10.1039/c7ra07179e

rsc.li/rsc-advances

\section{Mechanical behaviour of Longmaxi black shale saturated with different fluids: an experimental study}

\author{
Shuwen Zhang, (D) ab Xuefu Xian, ${ }^{\text {ab }}$ Junping Zhou*ab and Liang Zhang ${ }^{\text {ab }}$
}

The fluid-shale interaction during carbon dioxide $\left(\mathrm{CO}_{2}\right)$ enhanced shale gas recovery processes may have significant influences on the mechanical behaviour of shale, and it is also of great importance for the longterm safety of $\mathrm{CO}_{2}$ geological sequestration in shale formations. In this work, shale samples from the Longmaxi formation in the Sichuan basin were used to investigate the mechanical properties and the acoustic emission (AE) behaviour of shale upon saturation with different fluids (water, brine, and $\mathrm{CO}_{2}-$ brine mixture with different $\mathrm{CO}_{2}$ phase states) at $45^{\circ} \mathrm{C}$. X-ray fluorescence (XRF) analysis results show that major element alterations occur after shale is treated with supercritical $\mathrm{CO}_{2}-$ brine and subcritical $\mathrm{CO}_{2}-$ brine, the element content of $\mathrm{Ca}, \mathrm{K}$ and $\mathrm{Al}$ in supercritical $\mathrm{CO}_{2}$-brine saturated shale was decreased by $16.7 \%, 5.8 \%$ and $6.3 \%$, respectively. Field emission scanning electron microscopy (FESEM) analysis results indicate that significant surface structural changes occur in shale after saturated with $\mathrm{CO}_{2}$ and brine. Furthermore, the uniaxial compressive strength (UCS) and elastic modulus $(E)$ of shale with different fluid saturation were decreased. Supercritical $\mathrm{CO}_{2}$ cause a greater reduction of UCS and $E$ compared to subcritical $\mathrm{CO}_{2}$ due to its higher adsorption capability and larger $\mathrm{CO}_{2}$ adsorption induced swelling. The maximum reduction in UCS and $E$ of shale was observed in the case of $\mathrm{CO}_{2}$-brine saturated samples, and the influence of the $\mathrm{CO}_{2}$ phase on the mechanical behaviour of shale under brine conditions is not negligible. The fracture propagation pattern changes in shale after fluid saturation are also explained by the AE analysis.

\section{Introduction}

With the rising international concerns over the issue of global warming, carbon dioxide emission (as a major contributing factor to global warming) reduction has become a major environmental challenge. ${ }^{1,2}$ In order to control the atmospheric concentration of carbon dioxide, many studies have been conducted to seek appropriate methods to decrease $\mathrm{CO}_{2}$ emissions, including the use of less carbon-intensive fuels, developing new energy sources, implementing carbon storage into the subsurface and increasing conservation of forests. ${ }^{1}$ Geological sequestration of $\mathrm{CO}_{2}$ in depleted oil and gas reservoirs, deep unminable coal seams, shale gas reservoirs, and saline aquifers is the most valid and economic choice for reducing $\mathrm{CO}_{2}$ emission into the atmosphere, which can mitigate global warming by storing billions of tons of $\mathrm{CO}_{2}$ emitted from stationary industrial sources. ${ }^{3-9}$ Moreover, shale gas reservoirs, due to their ultra-low permeability and high storage potential, have received more attention for $\mathrm{CO}_{2}$ storage recently. ${ }^{10-13}$

${ }^{a}$ State Key Laboratory of Coal Mine Disaster Dynamics and Control, Chongqing University, Chongqing 400030, China.E-mail: zhoujp1982@sina.com

${ }^{b}$ College of Resource and Environment Science, Chongqing University, Chongqing 400030, China
Shale formations play important roles in large scale $\mathrm{CO}_{2}$ sequestration. In addition, shale gas, as an unconventional natural gas, is an alternative energy source and has become an increasingly important source of gas all over the world. The recoverable global shale gas resources are estimated to be approximately $2.07 \times 10^{14} \mathrm{~m}^{3}$, accounting for $32 \%$ of the total natural gas resources of the world. ${ }^{14}$ Injecting $\mathrm{CO}_{2}$ into organicrich gas shale not only allows the possibility of storing $\mathrm{CO}_{2}$ in shale formation but also enhances the gas recovery. The injected $\mathrm{CO}_{2}$ trapped in the subsurface through a number of mechanisms including solubility, residual trapping, mobility trapping and mineral trapping, while solubility trapping is the main trapping mechanism for rock mineral alteration. ${ }^{15}$ The $\mathrm{CO}_{2}$ storage capacity of the shale reservoirs are linked to the combination of aqueous solubility, chemical reaction, and physical sorption of $\mathrm{CO}_{2}$ in the shale. ${ }^{16,17}$ Injecting $\mathrm{CO}_{2}$ into shale formations would induce the swelling of shale matrix due to $\mathrm{CO}_{2}$ adsorption, which in turn weaken the mechanical properties of the shale by generating micro fracture. ${ }^{\mathbf{1 0}}$ Furthermore, the mechanical properties of shale are related to the shale gas reservoir conditions. Shale contains clay minerals is characterized as fine-grained, highly compacted and anisotropy sedimentary rock. The mineralogical and microstructural changes occur in reservoirs after $\mathrm{CO}_{2}$ injection may have a strong influence on the formation's integrity. ${ }^{18}$ 
$\mathrm{CO}_{2}$ is also an acidic and corrosive gas, and $\mathrm{CO}_{2}$ will most likely be at either a liquid or gaseous phase state after injected into shale gas reservoir. Although wells have been mostly dewatered or pumped off, there is still residual water in the reservoir, therefore, water and brine in the reservoir should be considered in the process of $\mathrm{CO}_{2}$ geological sequestration. After $\mathrm{CO}_{2}$ is injected into shale formation, it is expected that $\mathrm{CO}_{2}$ will be dissolved into water or brines in the target reservoirs and form carbonic acid, which changes the acid-base equilibrium and will react with the solid matrix. As the depth increases, $\mathrm{CO}_{2}$ exists in its supercritical state because temperature and pressure surpass the critical value (critical temperature: $31.04{ }^{\circ} \mathrm{C}$, critical pressure: $7.38 \mathrm{MPa}$ ). At this state, compared to subcritical $\mathrm{CO}_{2}$, supercritical $\mathrm{CO}_{2}$ exhibits unique characteristics such as low viscosity, high diffusivity, high density and solubility. ${ }^{19}$ It can easily penetrate into the matrix of the shale to dissolve the nonpolar and weakly polar material in shale. ${ }^{19}$ The specific properties of $\mathrm{CO}_{2}$ add to the complexity of the assessment of leakage scenarios. Hence, in order to evaluate the long-term safety of $\mathrm{CO}_{2}$ sequestration in shale gas reservoirs, it is necessary to conduct research on $\mathrm{CO}_{2}$-induced mechanical behaviour changes in shale.

In recent years, many researchers ${ }^{12,20-24}$ have investigated the influence of $\mathrm{CO}_{2}$ on rock mass chemical and physical structures. Busch et al. ${ }^{25}$ invested the interaction between $\mathrm{CO}_{2}$ and different clays in caprock, and its influence on the seal integrity of caprock. Farquhar et al. ${ }^{26}$ reported the mineral and porosity variations of sandstones and siltstones after reacting with supercritical $\mathrm{CO}_{2}$ in low-salinity water at in situ reservoir conditions for 16 days. The results showed that there is a decrease in calcite content of $2 \mathrm{vol} \%$ and an increase in porosity of $1.1 \mathrm{vol} \%$ after reaction. $\mathrm{CO}_{2}$-water-rock interactions also causes cap rock deformation, which results in the change of effective stress and stress-induced permeability. Ranathunga et $a .^{20}$ studied chemical and physical structural alteration in coal associated with $\mathrm{CO}_{2}$ adsorption and its effects on the mechanical properties of coal. The results indicated that $\mathrm{CO}_{2}$ adsorption causes the modification of mechanical properties, and strength reduction in low rank coal. Lamy-Chappuis ${ }^{21}$ demonstrated that both seismic velocity and rock strength were significantly reduced due to minor calcite dissolution during fluid substitution from brine to supercritical $\mathrm{CO}_{2}$. Wang et al. ${ }^{27}$ revealed appreciable changes in mineralogical compositions of powdered rock sample interact with $\mathrm{CO}_{2}$ and brine, and found that the contents of quartz, plagioclase, illite and chlorite increased significantly, whereas the contents of illite/smectite, biotite and kaolinite in lithic sandstone decreased more or less after reaction with $\mathrm{CO}_{2}$-brine. Qin et al. ${ }^{19}$ observed the influence of supercritical $\mathrm{CO}_{2}$ on the water wettability of shale, and concluded that the ratio of $\mathrm{C}$ and $\mathrm{Si}$ in the shale increased while the ratio of $\mathrm{O}, \mathrm{Ca}, \mathrm{Mg}$, and $\mathrm{H}$ decreased after supercritical $\mathrm{CO}_{2}$ treatment. However, most studies on the $\mathrm{CO}_{2}$-rock interaction were focused on the adsorption ${ }^{28}$ and microstructure characteristics of rock, ${ }^{12,29}$ and the object of most investigations are mainly focused on coal ${ }^{30,31}$ and sandstone. ${ }^{21}$ There are limited research efforts in regard to the $\mathrm{CO}_{2}$-induced mechanical behaviour of the shale saturated with water and brine.
Knowledge of $\mathrm{CO}_{2}$ saturation effect on the mechanical properties of shale are of great importance for long-term safety prediction of $\mathrm{CO}_{2}$ sequestration. The purpose of this study is to investigate the effects of the interaction of $\mathrm{CO}_{2}$-brine-rock and $\mathrm{CO}_{2}$-rock systems on the mechanical properties of shale under subcritical and supercritical phase states of $\mathrm{CO}_{2}$. In addition, an acoustic emission (AE) system was coupled to identify the stress threshold values of crack closure, crack initiation and crack damage for each testing condition during the uniaxial compressive strength experiment. Moreover, XRF and FESEM analyses were carried out to verify the results. The results of this research has significant implication on the long-term safety evaluation of the $\mathrm{CO}_{2}$ sequestration in shale formations and can provide guidance for $\mathrm{CO}_{2}$ enhanced shale gas recovery.

\section{Materials and methods}

\subsection{Sample description}

The shale samples used in this study were collected from an outcrop of the lower Silurian Longmaxi formation located in the Changning region of the Sichuan Basin (Fig. 1), where is currently one of the promising shale gas producing areas in China. ${ }^{32}$ The shale from the outcrop is distributed continuously and well stratified, with clear laminations. The thickness of the shale ranges from $100 \mathrm{~m}$ to $700 \mathrm{~m}$ and with an average of $500 \mathrm{~m}$. The total organic carbon of the shale is $7.88 \%$ and the vitrinite reflectance value is $2.85 \%$. These values indicate that this shale is optimal for the occurrence of shale gas. ${ }^{33}$ The X-ray diffraction (XRD) mineralogical composition of this shale sample is shown in Table 1. The XRD measurement data were collected over a $2 \theta$ range of $2-45^{\circ}$ at a scan rate of $0.02^{\circ} / 2 \mathrm{~s}$. According to Table 1 , the mineral composition selected shale is mainly composed of quartz, dolomite and calcite with the total content over than $70 \%$. Mineral composition is a critical factor for the mechanical properties evaluation of rocks. Generally, rock brittleness index increases with the increase of brittle minerals content.

\subsection{Sample preparation}

Shale is characterized as a highly anisotropy rock since bedding structure is well developed in shale formations, and anisotropy

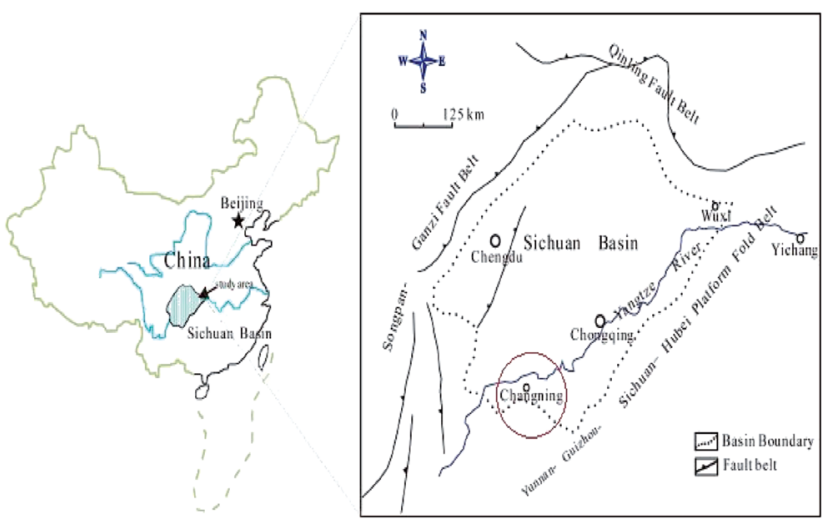

Fig. 1 The location of the study area in Sichuan Basin and the main structural elements in Sichuan Basin (modified from ref. 32). 
Table 1 Mineralogical composition of the shale sample (wt\%)

\begin{tabular}{lcl}
\hline $\begin{array}{l}\text { Mineralogical } \\
\text { Analysis }\end{array}$ & $\begin{array}{l}\text { Value } \\
(\%, \mathrm{wt})\end{array}$ & Chemistry \\
\hline Quartz & 44.8 & $\mathrm{SiO}_{2}$ \\
Dolomite & 19.8 & $\mathrm{CaMg}\left(\mathrm{CO}_{3}\right)_{2}$ \\
Clay & 8.1 & $\mathrm{Al}_{2} \mathrm{Si}_{2} \mathrm{O}_{5}(\mathrm{OH})_{4} / \mathrm{K}_{1.5} \mathrm{Al}_{4}\left(\mathrm{Si}_{6.5} \mathrm{Al}_{1.5} \mathrm{O}_{20}\right) \mathrm{OH}_{4}$ \\
Calcite & 13.9 & $\mathrm{CaCO}_{3}$ \\
Plagioclase & 3.5 & $\mathrm{NaAlSi}_{3} \mathrm{O}_{8}$ \\
Iron pyrites & 5.1 & $\mathrm{FeS}_{2}$ \\
Barite & 1.0 & $\left.\mathrm{Ba}_{\left(\mathrm{SO}_{4}\right)}\right)$ \\
K-Feldspar & 1.4 & $\mathrm{~K}_{2} \mathrm{OAl}_{2} \mathrm{O}_{3} 6 \mathrm{SiO}_{2}$ \\
Karstenite & 0.4 & $\mathrm{CaSO}_{4}$
\end{tabular}

has a significant effect on mechanical properties of shale. To prepare samples for analysis, a chunk of shale in a horizontal plane was chosen due to the anisotropy of the shale and avoiding inconsistencies in results. Cylindrical cores were drilled perpendicular to the bedding planes, the cores were $100 \mathrm{~mm}$ in length with a length to diameter ratio of 2 , and then grounded and polished to make smooth parallel surfaces for testing.

\subsection{Methodology}

The samples were tested for their mechanical strengths in terms of stress-strain behaviour, compressive strength, elastic modulus and acoustic emission patterns under different saturation conditions of the shale. Shale cores were considered with subcritical $\mathrm{CO}_{2}(6 \mathrm{MPa})$ and with supercritical $\mathrm{CO}_{2}(12 \mathrm{MPa})$ saturation, and both samples included dry and brine saturation (with $\mathrm{NaCl}$ concentrations of $10 \%$ by weight), the volume of water and brine are keeping the same and just swamp the shale sample. In addition, the dry, wet and brine saturated samples without $\mathrm{CO}_{2}$ injecting were compared. Fourteen samples were prepared for testing and each two samples were set as a groups for comparisons. Shale specimens were saturated with fluid by using a high pressure reactor, the actual laboratory setup used for saturation is shown in Fig. 2. The setup is mainly consisted of ISCO pump, thermostatic water bath with a relative uncertainty of less than $\pm 0.2{ }^{\circ} \mathrm{C}$ and high pressure reactor with a maximum pressure of $50 \mathrm{MPa}$. Before saturation, the reactor was filled with brine or water for submerging the sample cores and $\mathrm{CO}_{2}$ was finally injected into the reactor at $6 \mathrm{MPa}$ or $12 \mathrm{MPa}$ pressure, then the reactor was placed in the thermostatic water bath. In this work, the saturation temperature was constantly set to $45^{\circ} \mathrm{C}$, the saturation time was set to one week. Although the saturation time is crucial for the test results, significant differences were observed among samples after treated one week. ${ }^{12}$ The Table 2 shows the summary of saturation mediums, saturation conditions and number of samples used for repetition in the experiment.

\subsection{Laboratory instruments}

2.4.1. X-ray fluorescence analysis. In order to analyse the variation of sample elements under different conditions, X-ray fluorescence spectrometer analysis (XRF-1800 from Shimadzu Corporation, Kyoto, Japan) was performed. Samples used in

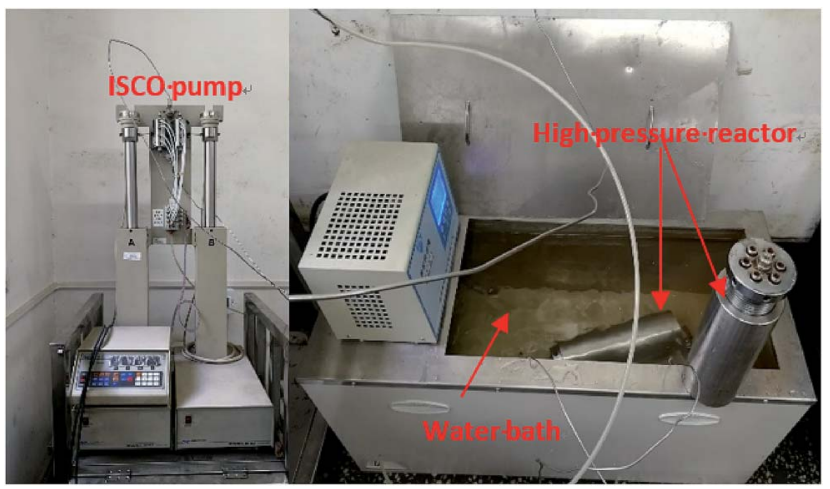

Fig. 2 The actual laboratory setup used for saturation.

Table 2 Summary of saturation condition

\begin{tabular}{lll}
\hline Saturation mediums & $\begin{array}{l}\text { Saturation } \\
\text { conditions }\end{array}$ & $\begin{array}{l}\text { Number } \\
\text { of samples }\end{array}$ \\
\hline Dry & $45^{\circ}$ & 2 \\
Water saturation & $45^{\circ}$ & 2 \\
Dry $+\mathrm{CO}_{2}$ saturation & $6 \mathrm{MPa}, 45^{\circ}$ & 2 \\
Dry $+\mathrm{CO}_{2}$ saturation & $12 \mathrm{MPa}, 45^{\circ}$ & 2 \\
$10 \% \mathrm{NaCl}$ & $45^{\circ}$ & 2 \\
$10 \% \mathrm{NaCl}+\mathrm{CO}_{2}$ saturation & $6 \mathrm{MPa}, 45^{\circ}$ & 2 \\
$10 \% \mathrm{NaCl}+\mathrm{CO}_{2}$ saturation & $12 \mathrm{MPa}, 45^{\circ}$ & 2
\end{tabular}

XRF analysis were required to press into flake with a diameter of $32 \mathrm{~mm}$, a thickness of $4 \mathrm{~mm}$ in a semi-automatic prototype.

2.4.2. Field-emission scanning electron microscopy (FESEM) analysis. The morphology and structure of the shale samples were characterized by using FESEM to identify possible interactions of the $\mathrm{CO}_{2}$-brine-shale and $\mathrm{CO}_{2}$-shale. FESEM analysis was performed using a TESCAN MIRA3 LMH instrument, the potential difference was set to $15 \mathrm{kV}$. During sample preparation, shale was crushed into particles and put together with the samples used for mechanical tests in the high pressure reactor under different conditions. Five types of samples under different conditions were used for FESEM analysis: brine saturation; $6 \mathrm{MPa} \mathrm{CO}_{2}$ saturation; $12 \mathrm{MPa} \mathrm{CO}_{2}$ saturation; $6 \mathrm{MPa}$ $\mathrm{CO}_{2}$-brine saturation and $12 \mathrm{MPa} \mathrm{CO}_{2}$-brine saturation.

2.4.3. MTS experiment equipment. Uniaxial compression strength tests were carried out on the MTS815 Rock Mechanics Test System manufactured by American MTS Corporation. Shale specimens were tested under displacement control and the loading rate was set at $0.05 \mathrm{~mm} \mathrm{~min}{ }^{-1}$, an automatic data acquisition system was used to record the loads and the strains of the samples for all the tests. All the tests were performed at room temperature.

2.4.4. Acoustic emission analysis. To identify the fracture propagation behaviour of samples saturated with different fluids, during the uniaxial compression strength testing, $\mathrm{AE}$ signals were collected by DISP Acoustic Emission Workstation and NANO-30 Acoustic Emission Sensor (both from the Physical Acoustics Corporation, USA). This setup is fully computerized and digitalized with multiple channels, low noise, low 
threshold, extra-fast data processing speed, and high reliability. In the USC test, the AE detection threshold value was set at 40 $\mathrm{dB}$, the frequency was set at $140 \mathrm{kHz}$, and the time parameters was set as: peak definition time $=50 \mathrm{~s}$, hit definition time $=$ $200 \mathrm{~s}$, and hit lockout time $=300 \mathrm{~s}$. To ensure successful signals detections, two probes were installed in the lateral of the specimens at the same height were used simultaneously, and both had a layer of grease applied to the part that touched the specimens to ensure a satisfactory coupling effect. The probes were further secured by rubber bands to prevent them falling off. After the AE acquisition system was installed, the AE signals were collected as the sample was stressed.

\section{Results}

\subsection{Minerals alterations of shale under different saturation conditions}

Table 3 shows the XRF test results of all the tested shale samples. The changes of elements content in shale are mainly depending on the reacting fluids. Considerable mineralogical structural changes in the shale samples were observed in the $\mathrm{CO}_{2}$ saturated samples and $\mathrm{CO}_{2}$-brine saturated samples, while there is no significant alterations occur for water saturated samples. This indicates that some complex chemical reactions and ions exchanges exist between the fluids and shale minerals. The XRF results illustrate that $\mathrm{Ca}$ element content in the subcritical $\mathrm{CO}_{2}$ saturated samples and the supercritical $\mathrm{CO}_{2}$ saturated samples are around $12.95 \%$ and $11.56 \%$ respectively, and these values are slightly lower by $0.4 \%$ and $10.9 \%$ respectively than that of the dry sample. Similarly, the same tendency can be seen in the element like K, Fe, and Al. However, S, Na and $P$ are almost remained unchanged. Compared to the elements of the dry sample, noticeable increase in Na concentration has been observed in the brine saturated samples with a percentage of $4.6 \%$, which indicates $\mathrm{Na}$ has entered into the shale matrix or pore system by ion exchange. In contrast to the slight changes observed in Ca under dry circumstance, calcium concentrations are of $10.83 \%$ and $10.34 \%$ in the subcritical $\mathrm{CO}_{2}$-brine and supercritical $\mathrm{CO}_{2}$-brine saturated samples respectively, with the changes of $16.7 \%$ and $20 \%$ respectively. Those changes show a significant reduction under the brine circumstance, and both of those changes in the subcritical $\mathrm{CO}_{2}$-brine and supercritical $\mathrm{CO}_{2}$-brine saturated samples are clearly larger than that of saturated with brine samples. Besides this, elemental concentration of $\mathrm{Fe}, \mathrm{K}, \mathrm{Mg}, \mathrm{Na}$ and $\mathrm{Al}$ were decreased with varying degrees, and more elements are involved in reactions than other saturation scenarios, which indicate the complexity mechanism of action in the subcritical $\mathrm{CO}_{2}$-brine and supercritical $\mathrm{CO}_{2}$-brine saturated samples. However, the changes of elements between subcritical $\mathrm{CO}_{2}$ and supercritical $\mathrm{CO}_{2}$ saturated samples are not obvious under the brine circumstance. These results are in consistency with the results from Qin et al. ${ }^{19}$ Wang et al. ${ }^{27}$ and Lu et al. ${ }^{34}$ However, the percentages of minerals alteration are not in the same, which may be related to the heterogeneous of the rock materials, such as different mineral compositions. In general, the intensity of the reaction between fluids and rocks may be related to the internal and external factors such as types of samples, reaction temperature, carbon dioxide pressure and phase states etc.

\subsection{Micro pore structure alternation under different saturation conditions}

The effects of reaction between fluids and shale samples can be confirmed by SEM analysis. The SEM results of the shale samples before and after saturation are shown in Fig. 3. We try to find the same position marked in SEM images, according to Fig. 3, significant structure changes occur after saturated with different fluids. For example, after $6 \mathrm{MPa} \mathrm{CO}_{2}$ and $12 \mathrm{MPa} \mathrm{CO}_{2}$ saturation, the surface of shale sample has become rougher due to the reaction and $\mathrm{CO}_{2}$ adsorption induced swelling occurred in shale (Fig. 3a and b). After saturated with brine, some pores are generated in shale, which indicates that ion exchanges may be happened. Moreover, significant corrosion and dissolution are found in $\mathrm{CO}_{2}$-brine saturated shale samples (As shown in the Fig. 3d and e marked A and B). Those micro structure alternation verifies the occurrence of minerals changes and mechanical behaviour variations to some extent after saturated with different fluids.

\subsection{Mechanical properties alterations of samples under different saturation conditions}

This section discusses the variations of mechanical properties (UCS, elastic modules) in tested shale samples with different saturation fluids. The inherent heterogeneity and anisotropy in shale specimens may lead to different strength characteristics,

Table 3 XRF test results of shale samples

Main elements/\%

\begin{tabular}{|c|c|c|c|c|c|c|c|c|c|c|}
\hline Samples & $\mathrm{O}$ & $\mathrm{Si}$ & $\mathrm{Ca}$ & $\mathrm{Al}$ & $\mathrm{Fe}$ & $\mathrm{K}$ & S & $\mathrm{Mg}$ & $\mathrm{Na}$ & $\mathrm{P}$ \\
\hline Dry & 41.40 & 34.62 & 13.00 & 3.65 & 2.52 & 1.56 & 1.03 & 1.06 & 0.89 & 0.06 \\
\hline Water & 41.53 & 34.57 & 12.98 & 3.63 & 2.52 & 1.52 & 1.03 & 1.05 & 0.88 & 0.06 \\
\hline Dry-6 $\mathrm{MPa} \mathrm{CO}_{2}$ & 41.60 & 34.57 & 12.95 & 3.63 & 2.50 & 1.54 & 1.04 & 1.05 & 0.89 & 0.06 \\
\hline Dry-12 $\mathrm{MPa} \mathrm{CO}_{2}$ & 42.25 & 35.62 & 11.56 & 3.48 & 2.43 & 1.42 & 1.03 & 1.10 & 0.86 & 0.05 \\
\hline Brine & 43.56 & 35.46 & 12.75 & 3.56 & 2.44 & 1.50 & 1.04 & 1.05 & 1.07 & 0.06 \\
\hline $6 \mathrm{MPa} \mathrm{CO}_{2}$-brine & 43.41 & 35.16 & 10.83 & 3.42 & 1.86 & 1.47 & 1.17 & 1.07 & 1.19 & 0.06 \\
\hline $12 \mathrm{MPa} \mathrm{CO}$-brine & 44.60 & 36.54 & 10.34 & 3.36 & 2.09 & 1.37 & 0.9 & 0.96 & 1.29 & 0.06 \\
\hline
\end{tabular}



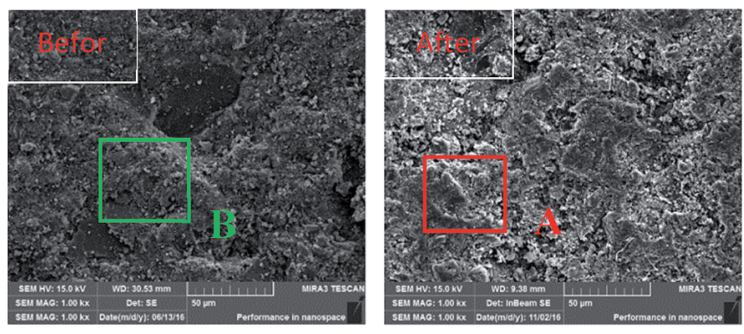

(a).6MPa $\mathrm{CO}_{2}$

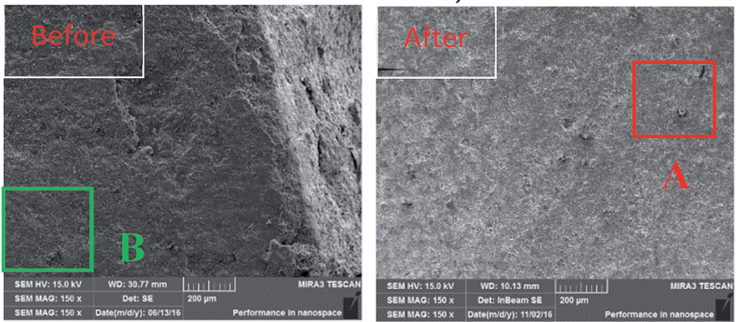

(b) $12 \mathrm{MPa} \mathrm{CO}$

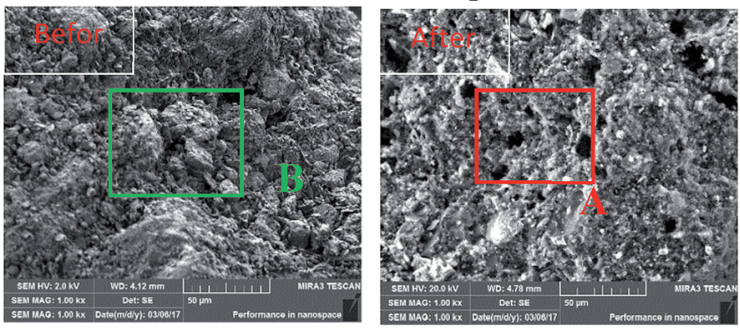

(c) Brine
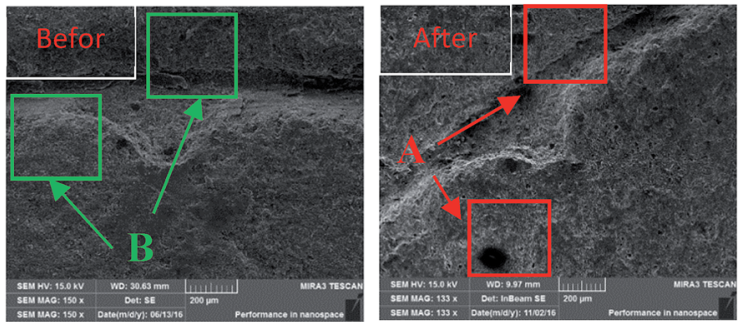

(d) $6 \mathrm{MPa} \mathrm{CO}_{2}+$ brine
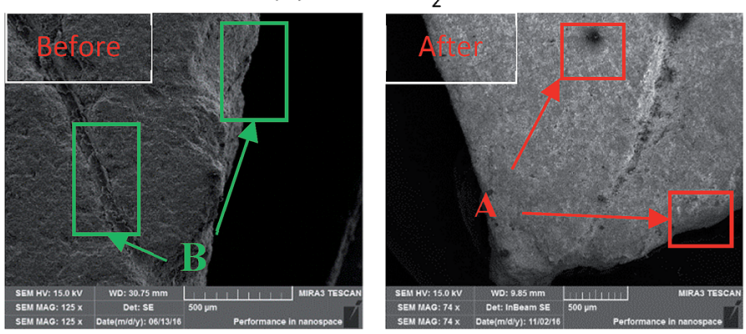

(e) $12 \mathrm{MPaCO}+$ +brine

Fig. 3 SEM results before and after fluids saturation.

in order to avoid these effects on the mechanical tests, two shale samples at each condition are selected in this study for comparison. Table 4 shows mean values of the uniaxial compressive strength, elastic modulus obtained for all the tested samples and changes in these values relative to values obtained from dry sample without saturating fluids. The differences in the obtained values for each group is very small, which indicate that the heterogeneous of the used samples is negligible. Then, the average value of each group is considered to represent the results of each test condition. The stress-strain curves obtained from those shale specimens saturated with different fluids are shown in Fig. 4. As seen from Fig. 4, the stress-strain curves of all of the tested shale samples exhibit similar trend during the whole loading process. With increasing stress, remarkable elastic deformation are generated and there is little plastic deformation appearing before brittle failure Results obtained for dry samples without fluids saturation are taken as benchmark value for comparison with the results obtained from different fluids saturated shale samples. The average values of UCS and elastic modulus for dry samples are 221.17 MPa and 19.18 GPa respectively, and there is a remarkable reduction of shale strength after fluids saturation.

Water interacts with the shale can affect the wellbore stability, shale caprock integrity and gas transport in shale. ${ }^{35}$ According to Table 4, the average value of UCS in water saturated shale samples is $162.58 \mathrm{MPa}$, which indicates that there is a clear strength reduction up to $26.5 \%$ in the tested shale after saturated with water. Interestingly, the strength reduction caused by water saturation is significantly lower than the values reported in the literature,$^{36}$ this may be associated with the heterogeneous of mineral composition and physical structure of different shales. Moreover, current study shows that UCS of dried shale could be overestimated due to natural water exists in the shale. Similar to the strength results, there is also a reduction $(16.2 \%)$ of elastic modulus in the water saturated shale. This indicates that large strain and brittleness decrease occurred in shale due to water saturation, which may influence the stability of the borehole in shale gas reservoir.

The average UCS values of subcritical (6 $\left.\mathrm{MPa} \mathrm{CO}_{2}\right)$ and supercritical $\mathrm{CO}_{2}\left(12 \mathrm{MPa} \mathrm{CO}_{2}\right)$ saturated shale specimens are 209.62 MPa and 199.90 MPa respectively. This corresponding to UCS reductions of $5.2 \%$ and $9.6 \%$ from dry samples respectively. Similarly, the elastic modulus reduced to $1.4 \%$ and $2.5 \%$ respectively for $\mathrm{CO}_{2}$ saturated samples, this indicates the shale ductile properties slightly improved due to $\mathrm{CO}_{2}$ adsorption. It is noted that supercritical $\mathrm{CO}_{2}$ caused a greater reduction of strength and elastic modulus in shale compared to subcritical $\mathrm{CO}_{2}$. It can be concluded that the influence of $\mathrm{CO}_{2}$ saturation on mechanical behaviour of the shale is dependent on the phase state of $\mathrm{CO}_{2}$.

The average UCS values of the shale specimens treated with $\mathrm{NaCl}$ solution ( $10 \%$ by weight) is $168.68 \mathrm{MPa}$, which is higher than that of water saturated shale and $\mathrm{CO}_{2}$-brine saturated shale, but lower than that of dry samples and $\mathrm{CO}_{2}$ saturated dry samples. Elastic modulus of brine saturated samples is higher than water saturated samples with a mild reduction of $4.8 \%$. This implies that the presence of $\mathrm{NaCl}$ leads to a higher strength and a higher shale's brittleness, these results are consistent with Shukla et al. ${ }^{37}$

The shale experiences further strength reduction after $\mathrm{CO}_{2}-$ $10 \% \mathrm{NaCl}$ solution saturation. The average UCS values of the $6 \mathrm{MPa} \mathrm{CO}_{2}$-brine and $12 \mathrm{MPa} \mathrm{CO}_{2}$-brine saturated samples are 149.63 $\mathrm{MPa}$ and $152.33 \mathrm{MPa}$ and respectively. This corresponding to UCS reduction of $32.3 \%$ and $31.1 \%$ for $6 \mathrm{MPa} \mathrm{CO}_{2}$ -brine and $12 \mathrm{MPa} \mathrm{CO}_{2}$-brine saturated samples respectively. 
Table 4 Mean values of USC and E obtained from all the tested samples and changes in these values relative to values obtained from testing of dry samples without saturating fluids

\begin{tabular}{|c|c|c|c|c|c|c|}
\hline \multirow[t]{2}{*}{ Dry } & 220.66 & 221.17 & - & 19.29 & 19.18 & - \\
\hline & 221.68 & & & 19.06 & & \\
\hline Water saturation & 164.60 & & & 16.52 & & \\
\hline \multirow[t]{2}{*}{ Dry-6 $\mathrm{MPa} \mathrm{CO}{ }_{2}$} & 209.63 & 209.62 & 5.2 & 19.02 & 18.92 & 1.4 \\
\hline & 209.60 & & & 18.81 & & \\
\hline \multirow[t]{2}{*}{$10 \% \mathrm{NaCl}$} & 167.36 & 168.68 & 23.7 & 18.06 & 18.25 & 4.8 \\
\hline & 170.36 & & & 18.44 & & \\
\hline \multirow[t]{2}{*}{$10 \% \mathrm{NaCl}-6 \mathrm{MPa} \mathrm{CO}$} & 147.68 & 149.63 & 32.3 & 15.07 & 15.56 & 18.9 \\
\hline & 151.67 & & & 16.05 & & \\
\hline \multirow[t]{2}{*}{$10 \% \mathrm{NaCl}-12 \mathrm{MPa} \mathrm{CO}_{2}$} & 150.64 & 152.33 & 31.1 & 15.45 & 15.84 & 17.4 \\
\hline & 154.01 & & & 16.22 & & \\
\hline
\end{tabular}

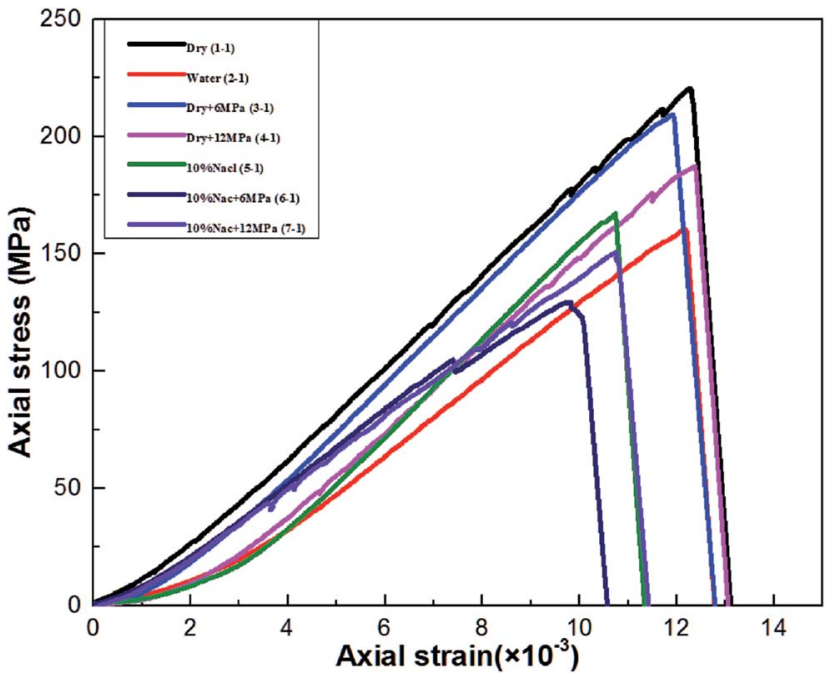

Fig. 4 The stress-train curves for shale specimens under different fluids saturation.

Similarly, average elastic modulus of the two groups are 15.56 GPa and $15.84 \mathrm{GPa}$ respectively, showing a reduction of more than $17 \%$. Interestingly, it can be seen that there are higher reductions of $6 \mathrm{MPa} \mathrm{CO}_{2}$-brine and $12 \mathrm{MPa} \mathrm{CO}_{2}$-brine saturated samples than that of brine saturated samples, which indicates that $\mathrm{CO}_{2}$ plays an important role in mechanical behaviour changing under brine circumstances. It is should be noted that the shale strength reductions of $6 \mathrm{MPa} \mathrm{CO}_{2}$-brine and $12 \mathrm{MPa} \mathrm{CO}_{2}$-brine saturated samples are much higher than that of only $6 \mathrm{MPa} \mathrm{CO}_{2}$ and $12 \mathrm{MPa} \mathrm{CO}_{2}$ saturated dry samples, which demonstrates that the combination effects of brine and $\mathrm{CO}_{2}$ have significant influence on the mechanical behaviours of shale. Furthermore, strength and elastic modulus values deviation observed in different $\mathrm{CO}_{2}$ phase-brine saturated shale samples are not negligible, which indicates that the phase state of the $\mathrm{CO}_{2}$ has significant influence on the mechanical behaviours of shale under the brine circumstance.

\subsection{Fracture propagation patterns of shale samples under different saturation conditions}

Acoustic and mechanical properties are sensitive to the evolution of microstructure and damage in rocks. ${ }^{38}$ The failure of a rock is a process by which internal micro-cracks are initiated, expanded, and eventually developed into macro-cracks. The process is usually accompanied by the generation of acoustic emission. The phenomenon of $\mathrm{AE}$, also called stress-wave emission, is the release of strain energy as elastic waves in the deformation process of a material or structure. Through analysing $\mathrm{AE}$ events, the stages of crack initiation, crack damage, and unstable crack propagation can be identified.

The crack closure stage is characterized by very little or no $\mathrm{AE}$ activities in the initial stages of the loading. With the increase of axial load, the elastic deformation takes place, stable crack propagation occurs and $\mathrm{AE}$ counts gradually increases in a linear manner, leading to the beginning of crack initiation. When tested specimens reach the crack damage point, $\mathrm{AE}$ counts increase drastically and unstable crack growth creates considerable damage and samples finally fail. In this study, the summation of AE counts versus axial loading stress for different fluids saturation are shown in Fig. 5. Stress thresholds of the shale under different saturation condition are listed in Table 5.

$\mathrm{AE}$ analysis is performed to understand the internal shale matrix response to external loading and exhibited the initiation and propagation process of fractures in shale. According to Fig. 5 and Table 5, water saturated sample shows crack initiation and crack damage stress at $66.44 \%$ and $92.06 \%$ of peak strength, compared to $68.33 \%$ and $93.69 \%$ for dry sample. While in case of brine saturated sample without $\mathrm{CO}_{2}$, crack initiation and crack damage stress are occurred at $60.10 \%$ and $88.61 \%$ of peak strength respectively. In addition, crack initiation is delayed as compared to crack damage due to the presence of $\mathrm{CO}_{2}$ in dry condition. While a reverse tendency is observed under $\mathrm{CO}_{2}$-brine condition, crack initiation and crack damage stress of subcritical $\mathrm{CO}_{2}$-brine saturated samples are occurred at $34.67 \%$ and $60.72 \%$ of peak strength, 


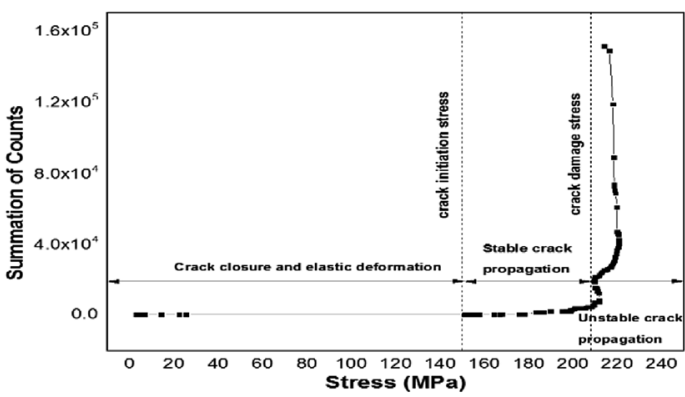

(a).Dry

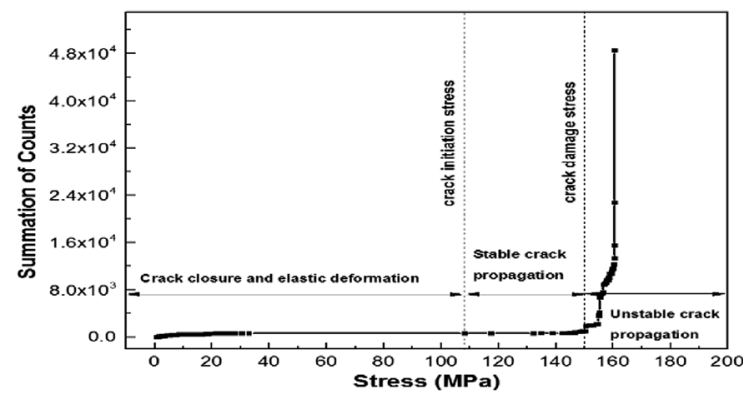

(b). Water saturation

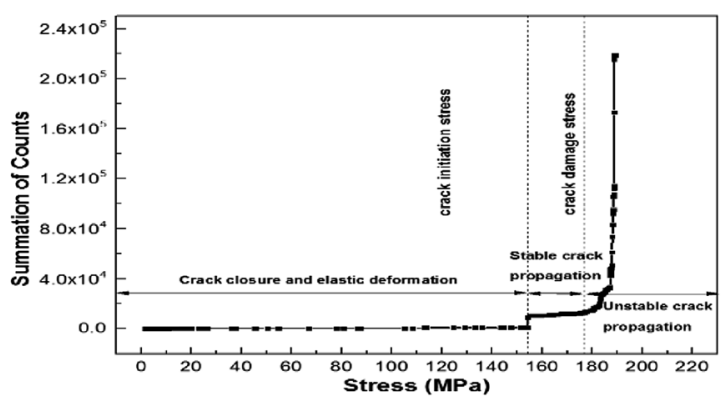

(c). Dry + $6 \mathrm{MPa} \mathrm{CO}_{2}$

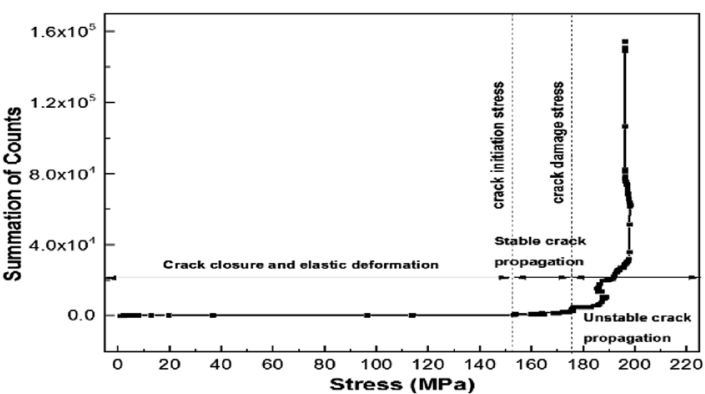

(d). Dry + $12 \mathrm{MPa} \mathrm{CO}$

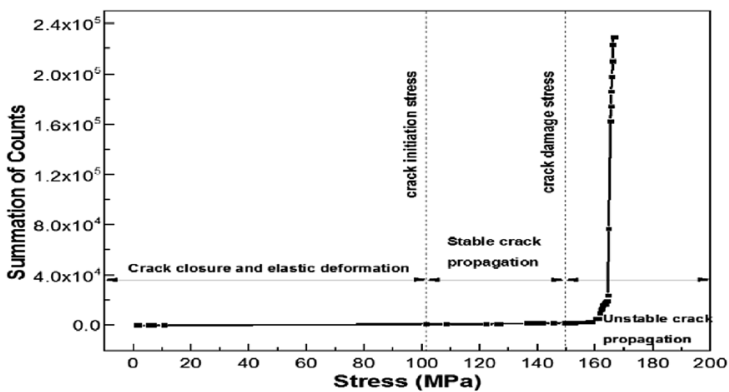

(e). $10 \% \mathrm{NaCl}$

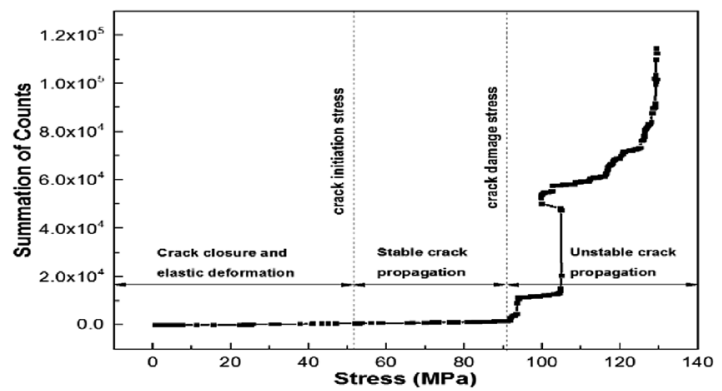

(f). $10 \% \mathrm{NaCl}+6 \mathrm{MPa} \mathrm{CO}_{2}$

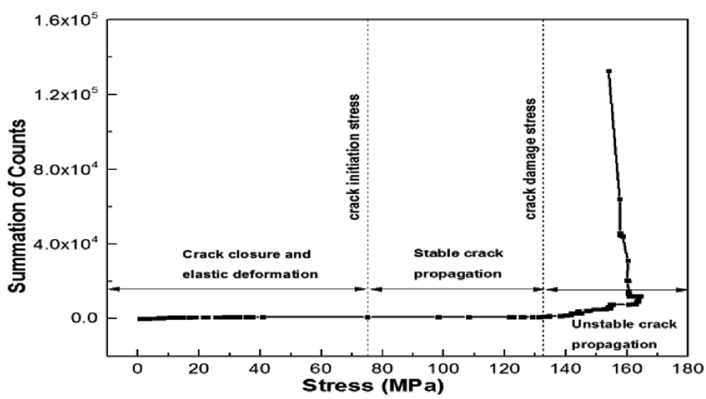

(g). $10 \% \mathrm{NaCl}+12 \mathrm{MPa} \mathrm{CO} 2$

Fig. 5 AE summation of counts versus stress for different fluid saturation.

for supercritical $\mathrm{CO}_{2}$-brine saturated samples, these two values are of $49.20 \%$ and $86.84 \%$ respectively. These results indicate that fluids saturation plays an important role in acoustic emissions patterns and mechanical behaviours of shale samples. When it is used to identify the mechanical behaviour of shale during the processes of $\mathrm{CO}_{2}$ geological sequestration, the fluid saturation effects should be considered.

\section{Discussions}

Once $\mathrm{CO}_{2}$ is injected into subsurface, it will interact with water phase and forms carbonic acid which releases active $\mathrm{H}^{+}$ions into system. ${ }^{18}$ As a consequence, free $\mathrm{H}^{+}$ions may react with some minerals during saturation period, then the structure of shale may be changed, and subsequently strength of shale will 
Table 5 Crack propagation stress thresholds values from AE analysis

\begin{tabular}{|c|c|c|c|c|c|}
\hline Saturation mediums & $\begin{array}{l}\text { Crack initiation } \\
\text { (MPa) }\end{array}$ & $\begin{array}{l}\text { Crack initiation } \\
\text { (\% of peak) }\end{array}$ & $\begin{array}{l}\text { Crack damage } \\
\text { (MPa) }\end{array}$ & $\begin{array}{l}\text { Crack damage } \\
\text { (\% of peak) }\end{array}$ & $\begin{array}{l}\text { Peak strength } \\
\text { (MPa) }\end{array}$ \\
\hline Dry & 151.15 & 68.33 & 207.21 & 93.69 & 220.66 \\
\hline Dry-6 $\mathrm{MPa} \mathrm{CO}_{2}$ & 151.59 & 72.32 & 176.78 & 84.30 & 209.63 \\
\hline Dry-12 $\mathrm{MPa} \mathrm{CO}{ }_{2}$ & 152.92 & 76.47 & 175.13 & 87.61 & 197.99 \\
\hline $10 \% \mathrm{NaCl}$ & 101.37 & 60.10 & 149.47 & 88.61 & 167.36 \\
\hline
\end{tabular}

be reduced. According to Pokrovsky et al. ${ }^{39}$ and Rochelle et al. ${ }^{40}$ mineralogical alteration mainly appears in carbonated cement, grain-to-grain contacts in pore and matrix of rock, calcite, kaolinite, dolomite, and K-feldspar may involve in reaction with free $\mathrm{H}^{+}$ions, leading to some minerals dissolution and new minerals generation. Such interactions including mechanical, chemical, physical, hydraulic and thermal effects are very complicated..$^{41}$ However, reaction between different saturation fluids and minerals of shale is dependent on $\mathrm{pH}$ value, ${ }^{42} \mathrm{CO}_{2}$ pressure, ${ }^{20}$ salinity of the saturation condition, ${ }^{18}$ reservoir temperature,$^{12}$ saturation time ${ }^{43}$ and the circumstance with or without water. ${ }^{34}$

In general, crystal water exists in shales and cannot be evaporated easily, these crystal water can combine with $\mathrm{CO}_{2}$ and form an acidic environment, then leads to the dissolution of minerals, which resulting in reduction of elements in shale after $\mathrm{CO}_{2}$ saturation. Besides this, the difference in minerals reduction between subcritical $\mathrm{CO}_{2}$ and supercritical $\mathrm{CO}_{2}$ saturated samples is due to the unique extraction effect of supercritical $\mathrm{CO}_{2}$, which can extract organic matters in shale, then further causing elemental changes in shale. ${ }^{12}$

The interaction of $\mathrm{CO}_{2}$-brine fluid with shale is very complicated, which involves in many types of minerals reactions. The XRF and FESEM results show that different fluids alter the content of main elements and change the structure of the shale samples at varying degrees (Table 3 and Fig. 3). Minerals alterations in $\mathrm{CO}_{2}$-brine saturated shale samples indicate that $\mathrm{CO}_{2}$ can be dissolved in water phase contained in brine and form weak acidity environments. Weak acid can dissolve the minerals in shale, such as K-feldspar and clay et al. Minerals dissolution might have significant influence on porosity, permeability, and diffusion properties by producing secondary cracks and pores in shale.

Fluids saturation will affect the microstructure and minerals compositions of shale, then leading to the strength and elastic modulus reduction in shale, and the reduction is greatly dependent on the type of saturation fluids. Water can easily move into matrix of shale, water and ion can be adsorbed onto the electrically charged surfaces of clay, which leading to the swelling and expansion of clay in shale. ${ }^{44}$ The adsorption of water causes the clay layers to separate, the shale skeletons and fabric alteration thus inducing internal expansive stresses. ${ }^{45}$ The influence mechanisms of water on the strength of shale include fracture surface energy reduction, capillary tension decrease, pore pressure increase, frictional reduction, and chemical deterioration. ${ }^{46}$ These five mechanisms could lead to weakening the mechanical properties and damaging the integrity of caprock during the $\mathrm{CO}_{2}$ sequestration processes.

As stated by Gibbs, ${ }^{47} \mathrm{CO}_{2}$ adsorption should theoretically reduce the surface energy of the rock mass. According to $\mathrm{Lu}$ et al. ${ }^{10} \mathrm{CO}_{2}$ adsorption-induced swelling occurs in shale, and with increasing $\mathrm{CO}_{2}$ pressure, the swelling of shale samples initially increases and then lessens. Besides, it is believed that supercritical $\mathrm{CO}_{2}$ has a greater adsorptive capacity compared to subcritical $\mathrm{CO}_{2}$, and causes to a greater rock matrix swelling. ${ }^{22}$ The swelling may change local stress regimes and cause the shale structure to be changed then reducing its overall strength. Moreover, it is difficult for $\mathrm{CO}_{2}$ to form carbonic acid due to shortage of the water phase in dry shale samples, but supercritical $\mathrm{CO}_{2}$ is capable of extracting organic matter in dry shale samples and dissolving the primary pores and fractures. ${ }^{12}$ Hence, as the supercritical $\mathrm{CO}_{2}$ has greater adsorptive potential, and stronger extracting and dissolving capacity, it causes a greater strength reduction in shale eventually.

Due to the presence of brine, the influence mechanism of the fluid on the mechanical behaviours of shale should be more complicated. The reduction of strength is due to the sensitivity or softening of the shale in the brine, ${ }^{48}$ the strength of brine saturated shale specimens is higher than water saturated shale specimens may be related to crystallization effect of $\mathrm{NaCl}$ in pore structure, which caused by salt evaporation. ${ }^{37}$ Besides, during the shale gas development, different chemicals have been added into drilling or fracturing fluids to control shale swelling, and interactions between shale and fluids vary with chemical compositions. Researchers have proved $\mathrm{NaCl}$ is an effective cationic inhibitors for clay swelling, ${ }^{49}$ thus, the extent of swelling of brine saturated shale is smaller than water saturated shale, resulting less damages of shale structure.

When $\mathrm{CO}_{2}$ is injected into brine, multiple phase fluids make the system more complex. Due to multiple effects arises from water phase, carbonic acid and brine, significant damages occur in the mechanical properties of the shale (Table 4). It is clear that $\mathrm{CO}_{2}$ solubility in brine is related to the gas pressure and the atmospheric temperature. ${ }^{50}$ It is no doubt that the $\mathrm{CO}_{2}$ solubility increases with gas pressure, and more minerals dissolution take place resulting more significant decrease in strength and elastic modulus. But carbonic acid is belong to weak acid, and mutual conversion among $\mathrm{H}_{2} \mathrm{CO}_{3}, \mathrm{HCO}_{3}{ }^{-}$and $\mathrm{CO}_{2}-\mathrm{H}_{2} \mathrm{O}$ is reversible. ${ }^{51}$ Moreover, the products by reactions with calcite, kaolinite, dolomite, and K-feldspar may buffer the hydronium 
content of the solution, ${ }^{\mathbf{1 7}}$ and after the supercritical $\mathrm{CO}_{2}+$ brine saturation, some minerals precipitation may be occurred and cement grain-to-grain contacts in the pore and matrix of the shale leading to enhance the mechanical properties of the shale. Thus, higher strength in the supercritical $\mathrm{CO}_{2}$-brine saturated samples occurs in test. From these observations, we can deduce that integrity of reservoir should be paid more attention when $\mathrm{CO}_{2}$ are injected into shale gas reservoirs.

The correlation of $\mathrm{AE}$ events versus applied stress to loaded specimens of shale can predict the threshold stresses for crack initiation and damage caused by uniaxial compression stress. ${ }^{52}$ Due to presence of fluids, fluids can diffuse through the rock matrix and generate chemical or physical adsorption with the rock matrix, leading to variation of the molecular structure including orientation of clay mineral, development and distribution of bonding structure, micro cracks and pore in the rock. ${ }^{53}$ Those structures play a dominant role in fracture propagation patterns of shale under uniaxial compression strength test. The crack initiation is delayed and crack damage occurs earlier in $\mathrm{CO}_{2}$ saturated samples, this phenomenon may be due to $\mathrm{CO}_{2}$ adsorption induced swelling. ${ }^{54}$ While the crack initiation and crack damage occur at lower percentage of peak strength in $\mathrm{CO}_{2}$-brine and brine saturated samples, this phenomenon can be explained by the view of mineral dissolution and water softening leading to damage of the shale.

\section{Conclusions}

Shale gas reservoirs are the ideal formation for $\mathrm{CO}_{2}$ geological sequestration, using the uniaxial compression strength test and $\mathrm{AE}$ technique, the mechanical properties and fracture propagation patterns of the shale saturated with different fluids were investigated. XRF and FESEM analysis were also performed to understand the effect of different fluids on the changes observed in the test. Some major conclusions were drawn as follows:

Elemental $\mathrm{Ca}, \mathrm{K}, \mathrm{Fe}$ and $\mathrm{Al}$ in shale significant decreased after brine saturation and $\mathrm{CO}_{2}$-brine saturation, this variation may be related to the reaction among brine, $\mathrm{CO}_{2}$ and minerals in shale.

Notable dissolution was observed in the $\mathrm{CO}_{2}$-brine and brine saturated samples from SEM images, while minor changes were found in other saturation condition. The water phase providing $\mathrm{H}^{+}$for forming carbonic acid is the main influence factor for these dissolution.

Fluids saturation can cause mechanical weakening of shale, and the reduction degree is greatly dependent on the type of the fluids. Water saturation and brine saturation have a prominent influence on the mechanical behaviour of shale. Supercritical $\mathrm{CO}_{2}$ saturation causes a greater reduction of strength and elastic modulus in shale than subcritical $\mathrm{CO}_{2}$ saturation due to its higher adsorption capacity and its own unique extraction ability. Maximum reduction in strength and elastic modulus of shale was observed in case of $\mathrm{CO}_{2}+$ brine saturation condition, which showed that $\mathrm{CO}_{2}$ dissolved in brine forming an acid, the dissolution effect of this acid leading to the further reduction of shale strength.
The crack initiation delayed and crack damage occurred earlier in $\mathrm{CO}_{2}$ saturated dry samples is related to $\mathrm{CO}_{2}$ adsorption induced swelling in shale. While the crack initiation and crack damage occurred at a lower percentage of peak strength during in $\mathrm{CO}_{2}$-brine and brine saturated samples may be due to mineral dissolution and water softening effects.

\section{Conflicts of interest}

There are no conflicts to declare.

\section{Acknowledgements}

This study was financially supported by the National Basic Research Program of China (2014CB239204), the Program for Changjiang Scholars and Innovative Research Team in University (IRT_17R112), the National Natural Science Foundation of China (51774060, 51574049), the Chongqing Frontiers and Application Foundation Research Program (CSTC2015jcyjys90001), the Fundamental Research Funds for the Central Universities (No. 106112016CDJZR245519) and Chongqing Land Bureau Science and Technology Planning project (No. KJ-2015040).

\section{References}

1 P. N. K. De Silva, P. G. Ranjith and S. K. Choi, Fuel, 2012, 91, 1-15.

2 P. N. K. De Silva and P. G. Ranjith, Int. J. Energy Res., 2014, 38, 60-69.

3 J. G. Wang, Y. Ju, F. Gao, Y. Peng and Y. Gao, J. Cleaner Prod., 2015, 103, 685-695.

4 V. Vishal, T. N. Singh and P. G. Ranjith, Fuel, 2015, 139, 51-58.

5 V. Vishal and P. G. Ranjith, SPE J. (Soc. Pet. Eng.), 2012, 1-9. 6 Z. Chen, X. Liao, X. Zhao, X. Feng, J. Zang and L. He, Int. J. Greenhouse Gas Control, 2015, 52, 46-59.

7 J. Lu, Y. K. Kharaka, J. J. Thordsen, J. Horita, A. Karamalidis, C. Griffith, J. A. Hakala, G. Ambats, D. R. Cole, T. J. Phelps, M. A. Manning, P. J. Cook and S. D. Hovorka, Chem. Geol., 2012, 291, 269-277.

8 Z. Zhang and D. Huisingh, J. Cleaner Prod., 2017, 142, 10551064.

9 M. C. Nguyen, X. Zhang, N. Wei, J. Li, X. Li, Y. Zhang, and P. H. Stauffer, Geomechanics and Geophysics for Geo-Energy and Geo-Resources, 2017, vol. 3, pp. 293-314.

10 Y. Lu, X. Ao, J. Tang, Y. Jia, X. Zhang and Y. Chen, J. Nat. Gas Sci. Eng., 2016, 30, 268-275.

11 D. Liu, Y. Li and R. K. Agarwal, Chem. Geol., 2016, 440, 288-305.

12 Y. Jiang, Y. Luo, Y. Lu, C. Qin and H. Liu, Energy, 2016, 97, 173-181.

13 R. S. Middleton, J. W. Carey, R. P. Currier, J. D. Hyman, Q. Kang, S. Karra, J. Jiménez-Martínez, M. L. Porter and H. S. Viswanathan, Appl. Energy, 2015, 147, 500-509.

14 EIA, 2011. 
15 S. M. V. Gilfillan, S. L. Barbara, H. Greg, B. Dave, S. Scott and S. Martin, Nature, 2009, 458, 614-618.

16 G. R. L. Chalmers and R. M. Bustin, Int. J. Coal Geol., 2007, 70, 223-239.

17 A. Busch, S. Alles, Y. Gensterblum, D. Prinz, D. N. Dewhurst, M. D. Raven, H. Stanjek and B. M. Krooss, Int. J. Greenhouse Gas Control, 2008, 2, 297-308.

18 T. D. Rathnaweera, P. G. Ranjith, M. S. A. Perera, A. Haque, A. Lashin, N. Al Arifi, D. Chandrasekharam, S. Q. Yang, T. Xu, S. H. Wang and E. Yasar, J. Mater. Sci. Eng. A, 2015, 641, 123-137.

19 C. Qin, Y. Jiang, Y. Luo, X. Xian, H. Liu and Y. Li, Energy Fuels, 2017, 31, 493-503.

20 A. S. Ranathunga, M. S. A. Perera, P. G. Ranjith and H. Bui, J. Supercrit. Fluids, 2016, 109, 134-140.

21 B. Lamy-Chappuis, D. Angus, Q. J. Fisher and B. W. D. Yardley, Int. J. Greenhouse Gas Control, 2016, 52, 84-95.

22 M. S. A. Perera, P. G. Ranjith, D. W. Airey and S. K. Choi, Fuel, 2011, 90, 3390-3397.

23 G. K. W. Dawson, S. D. Golding, P. Massarotto and J. S. Esterle, Energy Procedia, 2011, 4, 3139-3146.

24 V. Vishal, P. G. Ranjith and T. N. Singh, J. Nat. Gas Sci. Eng., 2015, 22, 428-436.

25 A. Busch, P. Bertier, Y. Gensterblum, G. Rother, C. J. Spiers, M. Zhang, and H. M. Wentinck, Geomechanics and Geophysics for Geo-Energy and Geo-Resources, 2016, vol. 2, pp. 111-130.

26 S. M. Farquhar, J. K. Pearce, G. K. W. Dawson, A. Golab, S. Sommacal, D. Kirste, D. Biddle and S. D. Golding, Chem. Geol., 2015, 399, 98-122.

27 K. Wang, T. Xu, F. Wang and H. Tian, Int. J. Coal Geol., 2016, 154-155, 265-274.

28 P. Li, Z. Jiang, M. Zheng, H. Bi and L. Chen, J. Nat. Gas Sci. Eng., 2016, 34, 1034-1043.

29 R. Lahann, M. Mastalerz, J. A. Rupp and A. Drobniak, Int. J. Coal Geol., 2013, 108, 2-9.

30 A. S. Ranathunga, M. S. A. Perera and P. G. Ranjith, Int. J. Coal Geol., 2016, 167, 148-156.

31 M. S. A. Perera, P. G. Ranjith and D. R. Viete, Appl. Energy, 2013, 110, 73-81.

32 G. Li and Z. Meng, J. Nat. Gas Sci. Eng., 2016, 36, 1220-1227.
33 C. H. Sondergeld, K. E. Newsham and J. T. Comisky, SPE J. (Soc. Pet. Eng.), 2010, 34, 23-25.

34 J. Lu, J.-P. Nicot, P. J. Mickler, L. H. Ribeiro and R. Darvari, Journal of Unconventional Oil and Gas Resources, 2016, 14, 72-85.

35 W. Yuan, X. Li, Z. Pan, L. D. Connell, S. Li and J. He, Energy Fuels, 2014, 28, 4925-4933.

36 T. Al-Bazali, Egypt. J. Pet., 2013, 22, 249-260.

37 R. Shukla, P. G. Ranjith, S. K. Choi, A. Haque, M. Yellishetty and L. Hong, Rock Mech., 2012, 46, 83-93.

38 M. Bai, Geomechanics and Geophysics for Geo-Energy and GeoResources, 2016, vol. 2, pp. 275-300.

39 O. S. Pokrovsky, S. V. Golubev, J. Schott and A. Castillo, Chem. Geol., 2009, 265, 20-32.

40 C. A. Rochelle, I. Czernichowski-Lauriol, A. E. Milodowski. 2004, 87-106.

41 J. Zhang, M. E. Chenevert, T. AL-Bazali and M. M. Sharma, Lect. Notes Comput. Sci., 2004, 3037, 388-395.

42 J. M. Ketzer, R. Iglesias, S. Einloft, J. Dullius, R. Ligabue and Vd. Lima, Appl. Geochem., 2009, 24, 760-767.

43 Q. Lyu, P. Ranjith, X. Long and B. Ji, Materials, 2016, 9, 663.

44 G. Chen, M. E. Chenevert, M. M. Sharma and M. Yu, J. Petrol Sci. Eng., 2003, 38, 167-176.

45 R. T. Ewy and R. J. Stankovich, North American Rock Mechanics Symposium, 2000, pp. 147-185.

46 E. M. V. Eeckhout, International Journal of Rock Mechanics and Mining Sciences \& Geomechanics Abstracts, 1976, vol. 13, pp. 61-67.

47 J. W. Gibbs, The Collected Works of J. W. Gibbs, Longmans, Green, New York, 1991, vol. 1, p. 219.

48 T. D. Rathnaweera, P. G. Ranjith and M. S. A. Perera, Fuel, 2014, 122, 1-11.

49 R. d. C. Balaban, E. L. F. Vidal and M. R. Borges, Appl. Clay Sci., 2015, 105-106, 124-130.

50 Y. Zhang, H. R. Lashgari, K. Sepehrnoori and Y. Di, Int. J. Greenhouse Gas Control, 2017, 57, 26-33.

51 J. Rohmer, A. Pluymakers and F. Renard, Earth-Sci. Rev., 2016, 157, 86-110.

52 P. Ranjith, M. Fourar, S. Pong, W. Chian and A. Haque, Int. J. Rock Mech. Min. Sci., 2004, 41, 43-48.

53 M. Mirzaeian and P. J. Hall, Energy Fuels, 2006, 2022-2027.

54 P. G. Ranjith, D. Jasinge, S. K. Choi, M. Mehic and B. Shannon, Fuel, 2010, 89, 2110-2117. 